\title{
Specification and quantitation of circulating immune complexes in the serum of patients with active pulmonary sarcoidosis
}

\author{
N Schoenfeld, B Schmolke, M Schmitt, N Remy, P Ellensohn, U Wahn, \\ R Loddenkemper
}

\begin{abstract}
Background - Circulating immune complexes can be elevated in serum samples of patients with sarcoidosis and are associated with disease activity, but their diagnostic significance is not understood. Methods - The different classes of circulating immune complexes containing immunoglobulin $A, G$, or $M$, and the content of complement in circulating immune complexes (polyethylene glycol precipitation) as well as levels of complement binding circulating immune complexes (complement binding assay) were determined in 19 patients with active, untreated pulmonary sarcoidosis. The results were compared with other parameters in the serum (soluble interleukin 2 receptor, angiotensin converting enzyme, immunoglobulin $A, G$, and $M$ ) and the bronchoalveolar lavage fluid (lymphocytes, helper cells, suppressor cells, activated $T$ cells), and with radiological stage and functional parameters $\left(\mathrm{FEV}_{1}\right.$, vital capacity, total lung capacity, transfer coefficient (KCO), and the alveolar-arterial oxygen difference during exercise).
\end{abstract}

Results - In all patients circulating immune complexes could be detected by polyethylene glycol precipitation and were similar to control subjects. The content of C1q in circulating immune complexes was higher than in controls, yet in all but one of the cases was still within normal limits. In contrast, elevated levels of complement binding circulating immune complexes were found in $67 \%$ of the patients. No correlation was seen between circulating immune complexes and any of the other parameters in the serum, bronchoalveolar lavage fluid, or lung function values. No differences were found between radiological type I and II presentations of sarcoidosis.

Conclusions - The complement binding assay showed a much higher sensitivity for the detection of circulating immune complexes in active pulmonary sarcoidosis than the polyethylene glycol precipitation method. As there was no correlation between levels of circulating immune complexes and other parameters of the disease they are probably not useful for the assessment of disease activity.

(Thorax 1994;49:688-691)
Sarcoidosis is a chronic multisystem disorder of unknown aetiology, characterised by various immunological processes. Although in the past several authors have reported elevated circulating immune complexes in serum samples of patients with sarcoidosis, ${ }^{1-4}$ the contribution of circulating immune complexes to the assessment of the disease activity is still under discussion. The uncertainty remains because of the use of various techniques for detection of circulating immune complexes, the association of the finding of circulating immune complexes with diverse parameters of the disease, and the unknown role of immune complexes in the pathogenesis of sarcoidosis.

The purpose of the present study was to evaluate the phenomenon in patients with clinically active, untreated disease combining two different quantitative methods with regard to the composition and biological functions of circulating immune complexes, thus following a WHO recommendation on their detection. ${ }^{5}$ The results were compared with a number of other parameters of the disease in serum and bronchoalveolar lavage fluid, with the radiographic appearances of the lung, and with lung function values.

\section{Methods}

\section{PATIENTS}

The study population consisted of five women and 14 men with a median age of 36 (range 2572) years. Seventeen were admitted to hospital for the first time after they had developed clinical symptoms including cough, dyspnoea on exertion, or an acute illness with erythema nodosum. Two untreated patients with previously diagnosed sarcoidosis had radiological evidence of progressive disease. The diagnosis in all patients was based on the histopathological finding of epithelioid cell granulomata and characteristic chest radiographic appearance. Eight of the patients had type I disease, 10 had type II, and one type III. For the evaluation of serum circulating immune complexes 10 healthy volunteers (seven men and three women with a median age of 39.5 (range 18$65)$ years) served as controls.

\section{LUNG FUNCTION}

Vital capacity (VC), total lung capacity (TLC), and forced expiratory volume in one second $\left(\mathrm{FEV}_{1}\right)$ were measured by whole body plethysmography. The single breathholding method

Revised version received 28 February 1994

5 April 1994 
was used to obtain the carbon monoxide transfer factor (TLCO). Reference values of the European Community for Coal and Steel (1983) were used. Progressive incremental work rate testing was performed using a cycle ergometer. During exercise the mixed expired concentrations of oxygen and carbon dioxide, the ECG, heart rate, expiratory flow, minute ventilation, and tidal volume were continuously monitored. Arterial blood gas tensions and alveolar-arterial oxygen difference (A$\mathrm{aDo}_{2}$ ) were measured at rest and at several exercise levels. The $\mathrm{A}-\mathrm{aDO}_{2}$ was considered abnormal if it was above $4.7 \mathrm{kPa}$ at the last step of exercise where steady state conditions were still present.

\section{BRONCHOALVEOLAR LAVAGE}

Bronchoalveolar lavage fluid was obtained during fibreoptic bronchoscopy. A total of $150 \mathrm{ml}$ sterile saline was instilled into a segment or subsegment of the middle lobe and recovered by gentle suction. After filtering through gauze and centrifugation the cells were washed with phosphate buffer saline $(\mathrm{pH}$ $7 \cdot 4$ ) and incubated with monoclonal antibodies labelled with phycoerythrin or fluorescein isothiocyanate. The following antibodies (Becton Dickinson, Heidelberg, Germany) were used: CD3 ( $\mathrm{T}$ cells), CD4 (helper cells), CD8 (suppressor/cytotoxic cells), HLA-DR/CD3 (activated $\mathrm{T}$ cells). The samples were analysed with a FACScan flow cytometer (Becton Dickinson). The size of lymphocyte fraction was calculated as a percentage of total cells and the size of lymphocyte subsets as a percentage of total lymphocytes.

\section{CIRCULATING IMMUNE COMPLEXES}

Polyethylene glycol precipitation (Fresenius, Oberursel, Germany)

Serum immune complexes were precipated at $2-8^{\circ} \mathrm{C}$ in the presence of polyethylene glycol (molecular weight 6000). After washing the precipitates were centrifuged and finally redissolved in a buffer. The concentration of IgG, IgA, IgM, and complement factors $\mathrm{C} 3 \mathrm{c}$ and $\mathrm{Clq}$ in the precipitates was determined by radial immunodiffusion using canine antisera. The evaluation after 48 hours was facilitated using Coomassie blue for staining of precipitate rings. The accuracy of the test was examined by simultaneous evaluation of human control serum. To obtain the reference range 500 random samples from European blood donors were tested for circulating immune

Table 1 Sensitivity threshold and upper normal limits $(\mu \mathrm{g} / \mathrm{ml})$ of complement binding circulating immune complexes (CIC) and circulating immune complexes containing $\operatorname{IgG}, \operatorname{Ig} A$, and $\operatorname{Ig} M$ antibodies and complement components $C 1 q$ and $C 3 c$.

\begin{tabular}{llcc}
\hline & Method & Sensitivity & $\begin{array}{c}\text { Upper } \\
\text { normal limit }\end{array}$ \\
\hline IgA-containing CIC & PEGP & 2 & 25 \\
IgG-containing CIC & PEGP & 4 & 110 \\
IgM-containing CIC & PEGP & 3 & 84 \\
Clq-containing CIC & PEGP & 2 & 88 \\
C3c-containing CIC & PEGP & 1 & 29 \\
Clq-binding CIC & CBA & 14 & 34 \\
C3d-binding CIC & CBA & 4 & 8 \\
\hline
\end{tabular}

PEGP = polyethylene glycol precipitation; $\mathrm{CBA}=$ complement binding assay. complexes using this test. The upper limits of the resulting tolerance limits (two standard deviations) are listed in table 1.

Complement binding assay (Medac, Hamburg, Germany)

Monoclonal antibodies against $\mathrm{Clq}$ or $\mathrm{C} 3 \mathrm{~d}$ complement components are bound to the solid phase of microtitre tubes. Circulating immune complexes in the serum sample react with the solid phase anti-Clq (anti-C3d). After washing peroxidase-linked mouse antihuman IgG was added which reacts with the $F c$ region of human IgG in circulating immune complexes. After incubation and repeated washing the enzyme substrate $(\mathrm{O}$ phenylenediamine and $\mathrm{H}_{2} \mathrm{O}_{2}$ ) was added which is oxidised in the presence of bound enzyme conjugate. The reaction was read in a spectrophotometer at $490 \mathrm{~nm}$ optical density after fixation with $4 \mathrm{~N} \mathrm{H}_{2} \mathrm{SO}_{4}$. The WHO standard for circulating immune complex assays was used to calibrate this system. Sera from 488 healthy persons were tested to define the reference ranges; $3 \%$ of the examined persons had circulating immune complex values above the upper limits shown in table 1 .

\section{OTHER SERUM PARAMETERS}

The concentration of serum IgG, IgA, and IgM was determined by laser nephelometry (Behringwerke, Marburg, Germany). The ELISA technique was used to determine serum levels of soluble interleukin 2 receptor (Immunotech, Marseille, France) and kinetic method was used to determine serum levels of angiotensin converting enzyme (Hermann Biermann, Bad Nauheim, Germany).

\section{STATISTICAL ANALYSIS}

The Mann-Whitney U test was used to compare group means. Correlations were made using the Pearson's correlation coefficient.

\section{Results}

The levels of circulating immune complexes in patients and controls are shown in table 2 . In two patients circulating immune complexes could be assessed by only one of the two methods. Circulating immune complexes could be detected by polyethylene glycol precipitation in all patients, and the values were similar to the healthy controls and exceeded the upper limit of normal in only two cases for IgM-containing circulating immune complexes. The content of $\mathrm{Clq}$ in circulating immune complexes was significantly higher than in controls $(p<0.05)$, but remained within normal limits in all but one case. The content of $\mathrm{C} 3 \mathrm{c}$ in circulating immune complexes was similar to the control subjects. In contrast, elevated levels of complement binding circulating immune complexes were found in $67 \%$ of the patients for both components using complement binding assay $(\mathrm{p}<0.01 v$ controls).

Results of bronchoalveolar lavage and other 
Table 2 Results of quantitative assessment $(\mu \mathrm{g} / \mathrm{ml})$ of circulating immune complexes (CIC) containing $\operatorname{IgA}, \operatorname{IgM}, \operatorname{IgG}, \mathrm{C1q}$, or $\mathrm{C} 3 \mathrm{C}(\mathrm{n}=18)$ and complement (C1q and C3d component) binding circulating immune complexes $(n=18)$ in sera of patients with sarcoidosis and controls $(n=10)$

\begin{tabular}{llccc}
\hline & Method & Median & Minimum & Maximum \\
\hline Sarcoidosis: & & & & \\
IgA-containing CIC & PEGP & 4 & $<2$ & 9 \\
IgG-containing CIC & PEGP & $<4$ & $<4$ & 94 \\
IgM-containing CIC & PEGP & 30 & 15 & 193 \\
C1q-containing CIC & PEGP & 28 & $<2$ & 126 \\
C3c-containing CIC & PEGP & 2 & $<1$ & 18 \\
C1q-binding CIC & CBA & 41 & $<14$ & 67 \\
C3d-binding CIC & CBA & 13.5 & $<4$ & 20 \\
& & & & \\
Controls: & PEGP & 3 & $<2$ & 7 \\
IgA-containing CIC & PEGP & $<4$ & $<4$ & 69 \\
IgG-containing CIC & PEGP & 15 & $<3$ & 67 \\
IgM-containing CIC & PEGP & $<2$ & $<2$ & 126 \\
C1q-containing CIC & PEGP & $<1$ & $<1$ & 9 \\
C3c-containing CIC & CBA & $<14$ & $<14$ & 29 \\
C1q-binding CIC & CBA & $<4$ & $<4$ & 4 \\
C3d-binding CIC & & & $<4$ \\
\hline
\end{tabular}

$\mathrm{PEGP}=$ polyethylene glycol precipation; $\mathrm{CBA}=$ complement binding assay

serum parameters are shown in tables 3 and 4. The mean vital capacity was $103 \%$ (range $75-$ $126 \%$ ) and the total lung capacity was $91 \%$ $(64-128 \%)$ of the predicted value. The mean $\mathrm{FEV}_{1}$ was $81 \%(65-93 \%)$ of vital capacity. The mean TLCo was $84.5 \%(52-123 \%)$ of the predicted value, and corrected for the alveolar volume (KCO) the mean value was $78 \%$ (49$108 \%$ ). The mean $\mathrm{A}-\mathrm{aDo}_{2}$ during exercise was $4.4 \mathrm{kPa}(1.9-9.0 \mathrm{kPa})$.

No correlation was found between different fractions of circulating immune complexes and any of the other parameters in serum, bronchoalveolar lavage fluid, or lung function tests. No significant differences in the levels of circulating immune complexes were found between types I $(n=8)$ and II $(n=10)$ as defined by radiology.

\section{Discussion}

The formation of immune complexes is part of the normal response to infectious agents or

Table 3 Lymphocyte fraction (\% of total cells) and lymphocyte subsets (\% of total lymphocytes) in bronchoalveolar lavage fluid of patients with sarcoidosis

\begin{tabular}{llll}
\hline & $n$ & Median & Range \\
\hline Lymphocytes & 19 & 37 & $12-89$ \\
CD3+ & 18 & $87 \cdot 5$ & $64-96$ \\
HLA-DR+/CD3+ & 17 & 57 & $29-85$ \\
CD4+ & 19 & 66 & $25-88$ \\
CD8+ & 19 & 12 & $6-40$ \\
CD4+/CD8 + ratio & 19 & $5 \cdot 4$ & $0 \cdot 6-14 \cdot 7$ \\
\hline
\end{tabular}

Table 4 Serum parameters in patients with sarcoidosis $(n=19)$

\begin{tabular}{lcccl}
\hline & Median & Range & $\begin{array}{l}\text { Upper } \\
\text { normal limit }\end{array}$ & $\begin{array}{l}\% \text { cases with } \\
\text { elevated values }\end{array}$ \\
\hline ACE (U/ml) & 50 & $24-82$ & 29 & 95 \\
SIL-2R (pmol/l) & 143 & $34-365$ & 115 & 58 \\
IgA (mg/dl) & 346 & $90-644$ & 280 & 32 \\
IgG (mg/dl) & 1660 & $1250-2230$ & 1600 & 58 \\
IgM (mg/dl) & 286 & $44-751$ & 280 & 53 \\
\hline
\end{tabular}

$\mathrm{ACE}=$ angiotensin converting enzyme; sIL-2R = soluble interleukin 2 receptor foreign substances. Whereas in most infectious or neoplastic diseases they can occur as a concomitant phenomenon without pathophysiological significance, in some chronic inflammatory diseases they may have a more important role. Immune complexes only induce immune complex disease when they are deposited in vessel walls and generate inflammation - for example, systemic lupus erythematosus, serum sickness, glomerulonephritis, or rheumatoid arthritis - and are usually eliminated by the mononuclear phagocytic system. ${ }^{8}$

The pathogenetic relevance of immune complexes depends on their size and composition which determines how fast they can be eliminated from the circulation and whether they are able to activate the complement cascade and cellular immune system. IgGcontaining immune complexes bind to $\mathrm{Fc}$ receptors on phagocytic cells, and immune complexes containing IgG or IgM can activate complement thus inducing chemotaxis. ${ }^{8}$ It therefore follows that methods of assessing circulating immune complexes should consider their physicochemical properties and biological functions. No fewer than 18 techniques were evaluated in a WHO study which recommended that one should always use two methods as different assays quite obviously measure different fractions of immune complexes and can vary considerably in their sensitivity. ${ }^{5}$

Several authors have tried to assess the clinical significance of elevated levels of circulating immune complexes in sarcoidosis in comparison with other parameters of the disease. Biglino et al used the conglutinin binding assay and found elevated levels of circulating immune complexes in 19 of 22 cases with a positive gallium-67 lung scan compared with six of 15 patients with a negative scan. ${ }^{3}$ Rooney et al demonstrated elevated levels of circulating immune complexes by the Raji cell assay in 11 of 14 patients with sarcoidosis who had both pulmonary and non-pulmonary features and a recent history of deterioration, some of whom were receiving treatment with systemic steriods. In contrast, only one of 17 treated or untreated patients considered stable was found to have an elevated level of circulating immune complexes. ${ }^{1}$ Kuehn et al used the non-quantitative method of immunofluorescence microscopy to detect circulating immune complexes after phagocytosis by granulocytes and found that they could be detected more frequently in patients with progressive disease. ${ }^{2}$ Of more interest, Saint-Remy et al found that levels of circulating immune complexes obtained by conglutinin binding assay were higher in patients with disease of more recent onset than in those with chronic disease. However, this finding was not reproducible when polyethylene glycol precipitation was used in the same patient group. ${ }^{4}$ These studies suggest that elevated levels of circulating immune complexes are more frequently seen in active and, particularly, acute disease.

In our study we used polyethylene glycol precipitation to identify different fractions of circulating immune complexes containing IgG, IgM, and IgA, as well as complement 
factors of the classic (Clq) and alternative (C3c) pathway. There was a tendency to higher levels of IgG-, IgM-, and IgA- containing classes of circulating immune complexes in the patient group, but values exceeded upper limits of normal in only two cases for IgMcontaining circulating immune complexes. Thus, not a single fraction of circulating immune complexes appeared to be responsible for the finding of elevated levels described in the previously mentioned studies. Using the much more sensitive complement binding assay abnormal levels of circulating immune complexes were found in two thirds of our patients for both complement factors $\mathrm{C} 1 \mathrm{q}$ and $\mathrm{C} 3 \mathrm{~d}$, indicating that the immune complexes are able to bind complement and hence could be pathogenic by inducing a complement cascade in vivo.

All our patients had clinical signs of active disease which was reflected in the frequent finding of elevated serum levels of angiotensin converting enzyme and soluble interleukin 2 receptor. However, correlation tests did not reveal a relation between the different fractions of circulating immune complexes and any of the other parameters in serum, and activation markers in bronchoalveolar lavage fluid such as $\mathrm{CD} 4+/ \mathrm{CD} 8+$ ratio and HLA-DR expression of T lymphocytes ${ }^{9}$ did not correlate with levels of circulating immune complexes. Serum immunoglobulins IgG, IgM, and IgA were also frequently elevated, indicating $B$ lymphocyte activation at sites of active disease where the immunoglobulins are secreted. ${ }^{10}$ Their production is polyclonal and obviously non-specific; ${ }^{11}$ the same could very well be true for the formation of immune complexes.

In spite of the frequent finding of elevated levels of circulating immune complexes in the serum of patients with sarcoidosis, we doubt that their evaluation can make a useful contribution to the clinical management of the disease. In contrast to other useful laboratory tests - particularly the varying sensitivity and precision of techniques used to measure circulating immune complexes - there remains an unsolved methodical problem which should always be considered before the interpretation of these test results in clinical management.

1 Rooney DP, Finch MB, Elborn, JS, Stanford CF. Circulating immune complexes in sarcoidosis, a clinical role for the Raji assay? Eur Respir $\mathcal{f} 1990 ; 3: 760-4$

2 Kuehn T, Rust M, Bartmann K, Meier-Sydow J. Zirkulierende Immunkomplexe und angiotensin-konvertierendes Enzym im Serum als Aktivitätsparameter bei Sarkoidose im Vergleich mit der bronchoalveolären Lavage. Prax Klin Pneumol 1987;41:856-7.

3 Biglino A, Albera C, Cariti G, Gioannini P. Relationship between circulating immune complexes, serum interferon and clinical features in sarcoidosis. Respiration and clinical

4 Saint-Remy JM, Mitchell DN, Cole PJ. Variation in immunoglobulin levels and circulating immune complexes in sarcoidosis. Am Rev Respir Dis 1983;127:23-7.

5 Lambert PH, Dixon FJ, Zubler RH. A WHO collaborative study for the evaluation of eighteen methods of detecting immune complexes in serum. F Clin Lab Immunol 1978;1:1-15.

6 Krapf F, Renger D, Schedel I, Leiendecker K, Leyssens H, Deicher H. A PEG-precipitation laser nephelometer technique for detection and characterization of circulating immune complexes in human sera. 7 Immunol Methods 1982;54:107-17.

7 Zubler RH, Lange G, Lambert PH, Miescher PH. Detection of immune complexes in unheated sera by a modified tion of immune complexes in unheated sera by a modi
${ }^{125} \mathrm{I}-\mathrm{Clq}$ binding test. $₹$ Immunol 1976;116:232-5.

8 Gilliland BC. Serum sickness and immune complexes. $N$ Engl $f$ Med 1983;311:1435-6.

9 Mueller-Quernheim J, Pfeifer S, Strausz J, Ferlinz R. Correlation of immunologic parameters of the inflammatory activity of pulmonary sarcoidosis. Am Rev Respir Dis 1991;144:1322-9.

10 Hunninghake GW, Crystall RG. Mechanisms of hypergammagloblulinemia in pulmonary sarcoidosis: site of increased antibody production and role of T-lymphocytes. $\mathcal{f}$ Clin Invest 1981;67:86-92.

11 Thomas PD, Hunninghake GW. Current concepts of the pathogenesis of sarcoidosis. Am Rev Respir Dis pathogenesis of 